Jurnal Keperawatan Wiyata

Volume 2, Nomor 1, Tahun 2021

ISSN 2774-4558 (Cetak)

ISSN 2774-9789 (Online)

\title{
KORELASI ANTARA ASPEK PSIKOSOSIAL DAN SPIRITUAL DENGAN PENYAPIHAN DINI PADA ANAK USIA BADUTA
}

\author{
Ayu Lestari ${ }^{1}$, Sumiati Sinaga ${ }^{2}$, Anik Puji Rahayu ${ }^{3}$ \\ ${ }^{1}$ Program Studi Keperawatan, ITKES Wiyata Husada, Jl. Kadrie Oening No. 77, \\ Samarinda, Kalimantan Timur \\ Gmail : manullangayu@gmail.com \\ ${ }^{2-3}$ Program Studi Keperawatan, ITKES Wiyata Husada, Jl. Kadrie Oening No. 77, Samarinda, \\ Kalimantan Timur \\ Gmail : sumiatisinaga@stikeswhs.ac.id, anikrahayu17@gmail.com
}

\begin{abstract}
ABSTRAK
Latar Belakang : Pemutusan pemberian ASI secara dini sangat mempengaruhi tumbuh kembang dan status kesehatan anak di masa depan. Ada kemungkinan proses penyapihan dini akan berpengaruh terhadap sistem cerna bayi yang belum siap, penyerapan nutrisi yang lebih sedikit, peningkatan berat badan berlebih dan resiko infeksi. Belum ada yang tahu kapan waktu yang tepat untuk mulai berhenti menyusui, namun ada baiknya dalam menekan turunnya angka kesakitan dan kematian bayi pemberian ASI eksklusif hingga usia 6 bulan dan dilanjutkan hingga usia 2 tahun dilakukan. Ibu yang berhenti memberikan ASI sebelum waktunya, dapat dipengaruhi oleh beberapa faktor, seperti kesehatan fisik ibu dan bayi, psikologis, sosial dan spiritual. Hal ini membuat peneliti tertarik untuk mengetahui aspek psikososial dan spiritual ibu yang melakukan penyapihan dini pada anak usia baduta Tujuan : untuk mengetahui korelasi antara aspek psikososial dan spiritual dengan penyapihan dini pada anak usia baduta. Metode : penelitian ini merupakan jenis penelitian kuantitatif dengan menggunakan rancangan deskriptif analitik dan pendekatan cross sectional. Jumlah sampel penelitian ini sebanyak 122 responden yang didapatkan menggunakan Simple Random Sampling dan pemberian kuesioner yang datanya di analisis dengan menggunakan uji Korelasi Pearson. Hasil : penelitian ini menunjukkan Ada korelasi yang bermakna (pvalue $=0.000$ ) dan sangat kuat $(\mathrm{r}=0.912)$ antara aspek psikososial dengan penyapihan dini pada anak usia baduta, sedangkan korelasi antara aspek spiritual dengan penyapihan dini ada korelasi bermakna (pvalue $=0.009)$ namun berkekuatan lemah $(\mathrm{r}=0.236)$. Kesimpulan : semakin baik nilai aspek psikososial dan spiritual seorang ibu saat menyusui maka akan semakin menurunkan tingkat penyapihan dini pada anak usia baduta.
\end{abstract}

Kata Kunci : Aspek Psikososial, Aspek Spiritual, Penyapihan Dini

\section{PENDAHULUAN}

ASI adalah makanan alamiah dari payudara ibu sebagai makanan optimal kepada bayi. ASI merupakan makanan paling baik untuk bayi, dengan komponen zat gizi yang ideal dan seimbang untuk dicerna dan diserap oleh bayi (Tri Windiarto et al, 2018). Menurut Keputusan Menteri Kesehatan RI No. 450/MENKES/SK/VI/2004, ASI eksklusif perlu diberikan pada bayi baru lahir sampai usia 6 bulan dan dilanjutkan sampai anak usia 2 tahun. Jika setiap bayi disusui secara eksklusif sejak lahir, maka angka kesakitan dan kematian bayi akan dapat diturunkan setiap tahunnya. Melihat makin tingginya angka penyakit menular dan tidak menular di Indonesia, penting bagi orangtua untuk memberikan pondasi dasar pertahanan tubuh yang baik bagi anak melalui ASI (Pollard, 2018). 
Menyusui tidak hanya sekedar memberi ASI kepada bayi, tetapi keduanya melakukan pertukaran sensasi emosional atau bounding yang memungkinkan terbentuknya pengembangan kepribadian mereka yang merasa dilindungi. Ketulusan, kepekaan dan stimulus diperlukan karena menyusui bukanlah perkara mudah tetapi juga bukan sesuatu yang sulit untuk dilakukan. (Alvarez \& Elena, 2018) Selain fakta bahwa ASI adalah makanan terbaik yang dapat diberikan ibu kepada bayi, menyusui merupakan ajaran agama. Semua agama menyarankan ibu untuk menyusui anak hingga anak merasa siap untuk berhenti. (Roesli, 2019) Kondisi ini sangat bergantung pada kualitas hubungan anak dan ibunya.

Masih banyak ibu yang sulit memberikan ASI secara optimal dengan berbagai latar belakang, sehingga masa menyusui ini akan berakhir disusul dengan masa sapih (Alvarez \& Elena, 2018). Penyapihan dini merupakan pemberhentian ASI kepada bayi sebelum usia enam bulan (Depkes RI, 1996). Menyapih lebih awal dapat dipengaruhi oleh mereka yang tidak mengerti dasar pemikiran mengapa harus menunggu sampai bayi berusia enam bulan dan mereka menerima panduan ini sebagai suatu hal yang dapat disesuaikan.

Menurut penelitian lain, keputusan penyapihan yang dilakukan oleh ibu ditentukan oleh karakteristik biologis dan fisiknya, tetapi dalam gilirannya perilakunya dipengaruhi oleh aspek psikologis (keinginan, motivasi, hambatan) dan oleh lingkungan sosial (tekanan dari orang lain). Ini adalah unit biopsikososial. (Alvarez \& Elena, 2018). Sedangkan menurut (Pollard, 2018) menegaskan kembali perlunya program menyusui untuk mempromosikan secara menyeluruh berbagai aspek positif sambil memberikan realistis informasi tentang tantangan dan strategi bersama untuk mengatasinya. Ibu membutuhkan dukungan individual yang menilai kebutuhan psikososial dan emosional dan menawarkan dorongan, kepastian, dan pengakuan dari berbagai pengalaman. Hasil studi pendahuluan pada 26 November 2019 dalam buku Pemantauan Wilayah Setempat Kesehatan Ibu dan Anak (PWS KIA) 2019 terdapat 350 bayi dari 473 bayi yang tidak mencapai ASI eksklusif di Puskesmas Harapan Baru. Pada bulan Desember 2019 peneliti juga melakukan wawancara kepada lima ibu yang membawa anak untuk imunisasi ke Puskesmas Harapan Baru, dari 5 ibu terdapat 4 ibu yang telah berhenti menyusui sebelum bayi usia 6 bulan. Dari 4 ibu tersebut terdapat 2 ibu berhenti menyusui di usia anak 3 bulan dengan alasan ibu sibuk bekerja dan suami menyarankan pemberian susu formula, 1 ibu mengatakan takut payudara nya 
kendur setelah menyusui sehingga tidak memberikan ASI lagi seminggu setelah kelahiran, 1 ibu lagi berhenti menyusui di usia anak 5 bulan karena ibu sudah menggantikan dengan MPASI sejak anak usia 4 bulan agar anak lebih kenyang dan mudah untuk tidur malam. Sedangkan 1 ibu yang masih memberikan ASI pada anak berusia 1 tahun saat itu, mengatakan bahwa payudara merupakan anugerah yang diberikan Tuhan untuk menyusui, sehingga ibu tetap berusaha memberikan yang terbaik. Dalam agama pun dijelaskan bahwa ibu wajib memberikan ASI. Penelitian ini bertujuan untuk mengidentifikasi korelasi antara aspek psikososial dan spiritual dengan penyapihan dini pada anak usia baduta di Puskesmas Harapan Baru Samarinda.

\section{METODE PENELITIAN}

Penelitian ini termasuk ke dalam penelitian kuantitatif. Rancangan deskriptif analitik dengan pendekatan cross sectional. Lokasi penelitian ini dilakukan di wilayah kerja Puskesmas Harapan Baru Samarinda pada tanggal 611 Juli 2020. Intrument penelitian meliputi Aspek Psikososial dan Aspek Spiritual dengan menggunakan google form dan angket tertulis yang dibagikan pada ibu yang telah melakukan penyapihan dini. Populasi dalam penelitian ini adalah ibu yang telah melakukan penyapihan dini pada anak sebelum 6 bulan yaitu sebanyak 346 orang ibu. Teknik sampling yang digunakan dalam penelitian ini adalah probability sampling dengan metode simple random sampling berdasarkan kriteria inklusi dan eksklusi. Sehingga sampel dalam penelitian ini berjumlah 122 orang ibu dengan analisa data menggunakan uji Korelasi Pearson.

\section{HASIL PENELITIAN}

Tabel 1 Distribusi Frekuensi Karakteristik Responden ( $\mathrm{N}=122)$

\begin{tabular}{|c|c|c|c|c|}
\hline No & Karakteristik & & $\begin{array}{c}\text { Frekue } \\
\text { nsi }\end{array}$ & $\%$ \\
\hline \multirow{3}{*}{1} & \multirow{3}{*}{ Usia Anak } & $\begin{array}{c}6-12 \\
\text { bulan }\end{array}$ & 73 & 59.8 \\
\hline & & $\begin{array}{l}12-18 \\
\text { bulan }\end{array}$ & 24 & 19.7 \\
\hline & & $\begin{array}{l}18-24 \\
\text { bulan }\end{array}$ & 25 & 20.5 \\
\hline \multirow{2}{*}{2} & \multirow{2}{*}{ IMD } & $\mathrm{Ya}$ & 96 & 78.7 \\
\hline & & Tidak & 26 & 21.3 \\
\hline \multirow{4}{*}{3} & \multirow{4}{*}{$\begin{array}{l}\text { Pendidikan } \\
\text { Terakhir }\end{array}$} & SD & 3 & 2.5 \\
\hline & & SMP & 6 & 4.9 \\
\hline & & SMA & 40 & 32.8 \\
\hline & & PT & 73 & 59.8 \\
\hline \multirow[t]{2}{*}{4} & \multirow{2}{*}{$\begin{array}{c}\text { Status } \\
\text { Pekerjaan }\end{array}$} & $\begin{array}{l}\text { Tidak } \\
\text { kerja }\end{array}$ & 54 & 44.3 \\
\hline & & Kerja & 68 & 55.7 \\
\hline \multirow{3}{*}{5} & \multirow{3}{*}{ Penghasilan } & $<1$ juta & 7 & 5.7 \\
\hline & & $1-2$ juta & 30 & 24.6 \\
\hline & & $>2$ juta & 85 & 69.7 \\
\hline
\end{tabular}

Sumber : Data Primer, 2020 Berdasarkan distribusi frekuensi tabel 1 diatas, terdapat mayoritas responden yang memiliki anak dengan usia 6-12 bulan sejumlah 73 orang (59.8\%), mayoritas responden yang melakukan inisiasi menyusui dini saat melahirkan anak sejumlah 96 orang $(78.7 \%)$, mayoritas responden yang memiliki pendidikan 
terakhir perguruan tinggi sejumlah 73 orang (59.8\%), mayoritas responden yang memiliki status pekerjaan yang sedang bekerja sejumlah 68 orang (55.7\%) dan mayoritas responden yang memiliki penghasilan/bulan $>2.000 .000$ sejumlah 85 orang $(69.7 \%)$

Tabel 2 Distribusi Statistik Berdasarkan Variabel $(\mathrm{N}=122)$

\begin{tabular}{ccccc}
\hline Variabel Mean & \multicolumn{2}{c}{ St. } & $\begin{array}{c}95 \% \\
\text { Median }\end{array}$ & CI \\
& & \multicolumn{3}{c}{ Deviasi } \\
\hline Penyapihan & & 4.00 & 0.974 & $3.44-$ \\
& 3.61 & & & 3.79 \\
Dini & & & & $18.74-$ \\
\hline Aspek & & 19.00 & 2.6 & 19.67 \\
Psikososial & 19.20 & & & $35.77-$ \\
\hline Aspek & & 36.00 & 3.759 & 37.12 \\
Spiritual & & & & \\
\hline
\end{tabular}

Sumber : Data Primer, 2020 Berdasarkan tabel 2 diatas, hasil analisis didapatkan rata-rata usia penyapihan dini bayi adalah 3.61 bulan, median 4 bulan, standar deviasi 0.974 bulan. Untuk estimasi interval $95 \%$ dengan rata-rata umur penyapihan berada pada selang $3.44 \mathrm{~s} / \mathrm{d}$ 3.79 bulan. Pada Aspek Psikososial hasil analisis didapatkan rata-rata aspek psikososial ibu adalah 19.20, median 19.00, standar deviasi 2.6. Untuk estimasi interval 95\% dengan rata-rata nilai aspek psikososial ibu berada pada selang 18.74 s/d 19.67. Sedangkan pada Aspek Spiritual hasil analisis didapatkan ratarata aspek spiritual ibu adalah 36.44, median 36.00, standar deviasi 3.759 . Untuk estimasi interval 95\% dengan rata- rata nilai aspek spiritual ibu berada pada selang $35.77 \mathrm{~s} / \mathrm{d} 37.12$.

Tabel 3 Distribusi Korelasi antara variabel Dependent dan Independent $(\mathrm{N}=122)$

\begin{tabular}{ccc}
\hline \multirow{2}{*}{ Variabel } & \multicolumn{2}{c}{ Penyapihan Dini } \\
\cline { 2 - 3 } & $\begin{array}{c}\text { Nilai } \mathbf{r} \\
\text { (korelasi) }\end{array}$ & Pvalue \\
\hline Aspek Psikososial & 0.912 & 0.000 \\
\hline Aspek Spiritual & 0.236 & 0.009 \\
\hline
\end{tabular}

Sumber : Data Primer, 2020

Berdasarkan Tabel 3 diatas, diperoleh hasil korelasi antara aspek psikososial dengan penyapihan dini yang memiliki nilai $\mathrm{r}=0.912$ yang artinya memiliki korelasi hubungan positif dengan kekuatan korelasi statistik yang sangat kuat dan Sig. $\quad$ (2-tailed) $=0.000$ yang menunjukkan bahwa pvalue $<0.05$ sehingga dapat disimpulkan aspek psikososial memiliki korelasi yang bermakna dengan penyapihan dini pada anak usia baduta di Puskesmas Harapan Baru. Sedangkan hasil korelasi hubungan antara aspek spiritual dengan penyapihan dini yang memiliki nilai Sig. (2tailed) $=0.009$ yang menunjukkan bahwa $\mathrm{p}<0.05$ yang artinya aspek spiritual memiliki korelasi yang bermakna, namun dari nilai $r=0.236$ artinya terdapat korelasi positif dengan kekuatan korelasi statistik lemah yang dapat disimpulkan bahwa hampir tidak ada korelasi antara aspek spiritual dengan penyapihan dini pada anak usia baduta di Puskesmas Harapan Baru Samarinda. 
Jurnal Keperawatan Wiyata

Volume 2, Nomor 1, Tahun 2021

ISSN 2774-4558 (Cetak)

ISSN 2774-9789 (Online)

Halaman 81-90

\section{PEMBAHASAN}

Berdasarkan hasil analisis korelasi aspek psikososial dengan penyapihan dini pada anak usia baduta didapatkan nilai $\mathrm{r}=0.912$ yang artinya kekuatan korelasi statistik sangat kuat dan Sig. (2tailed $)=0.000 \quad$ yang menunjukkan bahwa pvalue $<0.05$ sehingga korelasi sangat bermakna dengan arah korelasi yang positif. Pada penelitian ini dapat disimpulkan bahwa terdapat korelasi positif yang bermakna dan berkekuatan sangat kuat antara aspek psikososial dengan Penyapihan Dini pada Anak Usia Baduta di Puskesmas Harapan Baru sehingga hipotesis $\mathrm{Ha}$ diterima dan $\mathrm{Ho}$ ditolak. Menurut asumsi peneliti hal ini dapat disebabkan karena kurangnya dukungan pada aspek psikososial yang dipengaruhi faktor internal seperti cara berfikir, rasa percaya diri, sikap, pengetahuan ataupun pengalaman seorang ibu mengenai menyusui dan faktor eksternal seperti lingkungan sosial, keluarga, petugas kesehatan dan media sosial sehingga penyapihan dini dapat dihindarkan sebelum waktunya. Karena tingginya penyapihan dini merupakan tanggungjawab semua pihak, bukan hanya seorang ibu.

Penelitian ini sejalan dengan penelitian Jeniawaty, dkk 2016 tentang Asuhan Keperawatan Psikososial pada Ibu Nifas dalam Menghadapi ASI belum Keluar pada 0-3 hari Pascasalin. Pada hasil penelitian menunjukan bahwa aspek psikososial yang mendukung akan mempengaruhi keberhasilan seorang ibu dalam memberikan ASI sehingga diharapkan penyapihan dini dapat diatasi. Berdasarkan hasil penelitian kesehatan psikologi, didapatkan ada hubungan antara psikologi ibu dengan pemberian ASI eksklusif, ini didukung oleh teori (Mufdlilah,2017) bahwa faktor kejiwaan ibu dapat berpengaruh pada pemberian ASI antara lain yaitu rasa percaya diri, kepribadian, kecemasan, kestabilan emosi sikap dan pengalaman menyusui dan sejalan dengan penelitian (Josefa, 2011).

Stres, cemas dan ketidakyakinan mempengaruhi produksi hormon yang berperan dalam proses menyusui.

Keadaan psikologis menyebabkan jumlah dan kualitas ASI berkurang dan menyebabkan mereka memberikan MPASI dan PASI sebelum waktunya. Produksi ASI sangatlah dipengaruhi oleh faktor kejiwaan, ibu yang selalu dalam keadaan tertekan, sedih, kurang percaya diri dan berbagai ketegangan bentuk emosional akan menurunkan volume ASI bahkan tidak akan terjadi produksi ASI dan untuk memproduksi ASI yang baik, ibu harus dalam keadaan tenang (Wulandari \& Sri, 2011).

Berdasarkan hasil analisis korelasi aspek spiritual dengan penyapihan dini pada anak usia baduta didapatkan nilai $\mathrm{r}=0.236$ yang artinya kekuatan korelasi 
statistik lemah dan Sig. (2-tailed) $=0.009$ yang menunjukkan bahwa pvalue $<0.05$ yang memiliki korelasi bermakna dengan arah korelasi yang positif. Pada penelitian ini dapat disimpulkan bahwa hampir tidak terdapat korelasi antara aspek spiritual dengan penyapihan dini pada anak usia baduta di Puskesmas Harapan Baru dengan hipotesis $\mathrm{Ha}$ ditolak dan $\mathrm{Ho}$ diterima.

Menurut asumsi peneliti hal ini dapat disebabkan karena ibu menyadari bahwa pemberian ASI eksklusif merupakan suatu perintah setiap agama yang menyarankan untuk diberikan kepada setiap anak sebagai bentuk hak dan cinta kasih yang wajib diberikan kepada anak melalui ibu. Walaupun ibu menyadari hal tersebut namun dalam kenyataannya, ibu belum mampu untuk memberikan apa yang seharusnya anak terima selama masa tumbuh kembangnya. Walaupun sepenuhnya bukan hanya tanggungjawab dari ibu, tetapi juga peran keluarga dan pasangan hidup sangatlah besar dalam hal ini. Penelitian ini sejalan dengan penelitian Rinanti tahun 2018 yang berjudul Status Kesehatan Ibu dengan Pemberian ASI Eksklusif. Pada hasil penelitian menunjukan bahwa aspek spiritual yang mendukung akan mempengaruhi keberhasilan seorang ibu dalam memberikan ASI sehingga diharapkan penyapihan dini dapat diatasi. Berdasarkan hasil penelitian Wattimena, dkk 2012, didapatkan bahwa ibu yang berhasil menyusui lebih dari 6 bulan mempunyai kesadaran diri untuk memaknai ASI. Ia menyadari akan kelebihan luar biasa dalam kandungan gizi, kekebalan, dan kedekatan yang terbentuk antara ibu dan anak. Hal-hal ini yang membanggakan dan memberi pengharapan agar anak mereka tumbuh menjadi anak yang cerdas. Pilihan menjadi ibu yang bertanggung jawab terhadap kebahagiaan dan keselamatan anak yang dilahirkan menyebabkan ibu sadar diri tentang keunggulan dan kekuatan spiritual ASI yang alami dan diberkahi Ilahi.

Berdasarkan hal ini, maka kita bisa mengatakan bahwa ASI merupakan makanan sempurna yang mengandung berbagai zat makanan yang sangat diperlukan oleh tubuh makhluk hidup, sehingga metabolisme tubuhnya bisa berjalan lancar dan perkembangan badannya berlangsung dengan baik. Ibu memaknai ASI dan mau menyusui. Ibu sadar bahwa menyusui adalah tugas yang mulia dan kewajiban tanpa pamrih. Walaupun berhadapan dengan berbagai tugas, tetapi tugas menyusui tetap nomor satu dan tidak tergantikan. Kebiasaan tidak menyusui adalah perbuatan yang menyia-nyiakan pemberian Tuhan Yang Maha Esa. Keyakinan Spiritual merupakan hal yang mempengaruhi tingkat kesehatan dan perilaku selfcare 
pasien. Dampak negatif dari tidak terpenuhinya kebutuhan spiritual dan dapat mengakibatkan seseorang lebih rentan terhadap depresi, stres, mudah gelisah, kehilangan kepercayaan diri dan kehilangan motivasi (Craven dan Hirnle, 2009). Ibu dan keluarga dalam upaya memberikan hak yang ditetapkan untuk mereka sesuai amanat dalam Al-Qur'an Surah Al-Baqarah: 233 (Kadir, 2014).

\section{KESIMPULAN}

1. Berdasarkan karakteristik responden saat ini banyak ibu yang memiliki anak berusia 6-12 bulan, dimana mayoritas ibu melakukan inisisasi menyusui dini ketika melahirkan anak. Sedangkan mayoritas pendidikan terakhir ibu yaitu Perguruan Tinggi dengan memiliki pekerjaan dan penghasilan $\mathrm{Rp}$.

$>2.000 .000,-/$ bulan.

2. Pengalaman ibu memperoleh dukungan pada aspek psikososial berbeda-beda. Ibu yang mendapatkan dukungan psikososial secara penuh dapat membantu hormon pembuat susu berproduksi secara maksimal yaitu prolaktin. Nilai ini diperoleh berdasarkan penilaian terhadap rasa percaya diri, penampilan dan perilaku, cara berfikir, perasaan atau ekspresi dari status emosional, proses intelektual (pengetahuan dan pendidikan), keterlibatan keluarga atau lingkungan, sikap, interaksi sosial.
3. Suatu hubungan yang dibangun oleh ibu dengan janin selama dalam kandungan merupakan hubungan baik, sama baiknya dengan ikatan fisik maupun emosional. Spiritualitas dapat memicu kesehatan dan penyembuhan, membawa seseorang pada mental and physical well-being yang lebih baik.

4. Kurangnya dukungan pada aspek psikososial yang dipengaruhi faktor internal seperti cara berfikir,rasa percaya diri,sikap, pengetahuan ataupun pengalaman seorang ibu mengenai menyusui ataupun faktor eksternal seperti lingkungan sosial, keluarga, petugas kesehatan dan media sosial sehingga penyapihan dini dapat dihindarkan sebelum waktunya. Dari hasil korelasi dapat disimpulkan semakin baik nilai aspek psikososial ibu maka semakin menurun usia bayi akan dilakukan penyapihan dini.

5. Ibu menyadari bahwa pemberian ASI eksklusif merupakan suatu perintah setiap agama yang menyarankan untuk diberikan kepada setiap anak sebagai bentuk hak dan cinta kasih yang wajib diberikan kepada anak melalui ibu. Dari hasil korelasi dapat disimpulkan semakin baik nilai aspek spiritual ibu maka semakin menurun usia bayi akan dilakukan penyapihan dini.

\section{SARAN}

1. Bagi Tenaga Kesehatan 
Jurnal Keperawatan Wiyata

Volume 2, Nomor 1, Tahun 2021

ISSN 2774-4558 (Cetak)

ISSN 2774-9789 (Online)

Halaman 81-90

Walaupun pada Aspek Spiritual di dapatkan korelasi yang lemah, Tenaga Kesehatan dan Kader diharapkan harus lebih intensif dalam memberikan informasi yang berkaitan dengan pentingnya aspek psikososial dan aspek spiritual pada ibu menyusui dengan pendekatan yang berwawasan sehingga diharapkan dapat menurunkan angka penyapihan dini pada anak usia baduta.

2. Bagi Peneliti Lain

Peneliti selanjutnya dapat memberikan cara untuk menurunkan kejadian penyapihan dini pada anak usia baduta.

\section{DAFTAR PUSTAKA}

Profil Perempuan Indonesia. (2018). Dipetik Februari 6, 2020, dari www.kemenpppa.go.id

Alcaf, M. (2017). Doa dan Zikir Khusus Wanita. Jakarta: Guepedia.

Alvarez, V. S., \& Elena, O. M. (2018). Aspek Psikososial Menyusui. Jurnal Ilmu Kedokteran, 95100.

Andriani, M., \& Wirjatmadi, B. (2012). $\begin{array}{ll}\text { Peranan Gizi dalam } & \text { dakarta: } \\ \text { Siklus Kehidupan. } & \text { Jakadadia Group. }\end{array}$

Asmadi. (2008). Teknik Prosedural Keperawatan Konsep dan Aplikasi. Jakarta: Salemba Medika.

Bagus Ani Putra, M. G., Herdiana, I., \& Alvian, I. N. (2012). Pengantar Psikologi Sosial. Surabaya: Airlangga University Press.
Banerjee, A. M. (2017). Nucleus. Jakarta: PT Gramedia Pustaka Utama.

Carsel, S. (2018). Metodologi Penelitian Kesehatan dan Pendidikan. Yogyakarta: Penebar Media Pustaka.

Desmariyenti, et al. (2018). Hubungan Pengetahuan dan Sikap Ibu dengan Waktu Penyapihan. Endurance, 500-509.

Djaiman, S. P. (2009). Besarnya Peluang Usia Penyapihan Anak Baduta di Indonesia dan Faktor yang Mempengaruhi. Media Litbang Kesehatan Volume XIX Nomor 1.

Hamid, A. Y. (2008). Bunga Rampai Asuhan Keperawatan Kesehatan Jiwa. Jakarta: Buku Kedokteran EGC.

Hanifah, S. A., Astuti, S., \& Susanti, A. I. (2017). Gambaran Karakteristik Ibu Menyusui Tidak Memberikan ASI Eksklusif di Desa Cikeruh Kecamatan Jatinagor Sumedang. Jurnal Sistem Kesehatan.

Havener, K. C. (2013). Nursies When the Sun Shines: A little book on nightweaning. Elea Press.

Hermawan, I. (2019). Teknik Menulis Karya Ilmiah Berbasis Aplikasi dan Metodologi. Kuningan: Hidayatul Quran.

Heryanto, E. (2017). Faktor-faktor yang Berhubungan dengan Pemberian Makanan Pendamping ASI Dini. Jurnal Ilmu Kesehatan 2, 141152.

Hindah, M. (2009). Hidangan Sehat untuk Ibu Menyusui. Jakarta: Gramedia Pustaka Utama. 
Jeniawaty Sherly et al. (2016). Asuhan Keperawatan Psikososial pada Ibu Nifas dalam Menghadapi ASI Belum Keluar pada 0-3 Hari Pascasalin. Jurnal Ners, 261268.

Josefa, K. G. (2011). Faktor-Faktor yang Mempengaruhi Perilaku Pemberian ASI Eksklusif pada Ibu. Artikel Penelitian Karya Tulis Ilmiah.

Juliandi, A., Irfan, \& Manurung, S. (2014). Metodologi Penelitian Bisnis Konsep dan Aplikasi. Medan: Umsu Press.

Kamariyah, N. (2014). Kondisi Psikologi Mempengaruhi Produksi ASI Ibu Menyusui di BPS ASKI Pakis Sido Kumpul Surabaya. Jurnal Ilmiah Kesehatan, 29-36.

Leurer, M. D., \& Misskey, E. (2015). The Psychosocial and Emotional Experience of Breastfeeding: Reflections of Mother. Global Qualitative Nursing Research, 2, 1-9.

Marimbi, H. (2010). Tumbuh Kembang Status Gizi dan Imunisasi Dasar pada Balita. Yogyakarta: Nuha Medika.

Maryati, K., \& Juju, S. (2006). Sosiologi (Vol. 2). Gelora Aksara Pratama.

Masturoh, I., \& Anggita, N. (2018). Metodologi Penelitian Kesehatan. Jakarta: Kementerian Kesehatan Republik Indonesia.

Monika, F. B. (2014). Buku Pintar ASI dan Menyusui. Jakarta Selatan: Noura Books.

Mubarak. (2007). Promosi Kesehatan Sebuah Pengamatan Proses
Belajar Mengajar dalam Pendidikan. Yoyakarta: Graha Ilmu.

Mufdlilah. (2019). Buku Panduan Ayah ASI. Yogyakarta: Nuha Medika.

Mulyani, N. S. (2013). ASI dan Panduan Ibu Menyusui. Yogyakarta: Nuha Medika.

Mulyani, N. S. (2013). ASI dan Pedoman Ibu Menyusui. Yogyakarta: Nuha Medika.

Nahar, M. (2018). Hubungan Spiritual Support dengan Kecemasan dan Adaptasi Spiritual Ibu Hamil. Perpustakaan Universitas Airlangga.

Ningrum, S. P. (2017). Faktor-faktor Psikologis yang Mempengaruhi Postpartum Blues. Psympathic: Jurnal Ilmiah Psikologi, 2052018.

Nurmala, I. (2018). Pormosi Kesehatan. Surabaya: Airlangga University Press.

Pambudi, J., \& Christijani, R. (2017). Praktek Penyapihan Dini serta Hubungannya dengan Keadaan Sosial Ekonomi dan Wilayah Tempat Tinggal. Pusat Penelitian dan Pengembangan Upaya Kesehatan Masyarakat, 87-94.

Pollard, M. (2018). ASI Asuhan Berbasis Bukti. Jakarta: EGC.

Praborini, A., \& Wulandari, R. A. (2018). Anti Stress Menyusui. Jakarta Selatan: PT. Kawan Pustaka.

Priyatna, A. (2012). Father's First Year Membahas Topik-Topik yang Penting Diketahui di Tahun Menjadi Ayah. Jakarta: Kelompok Gramedia. 
Purwanti, H. S. (2004). Konsep Penerapan ASI Eksklusif. Jakarta: EGC.

Rahmat, I. (2016). Aspek Spiritual dalam Keperawatan.

Yogyakarta: EGC.

Ramayulis, R., \& Marbun, R. M. (2010). Menu dan Resep untuk Ibu Menyusui. Jakarta: Penebar Plus.

Riksani, R. (2013). Dari Rahim Hingga Besar. Jakarta: PT Elex Media Komputindo.

Roesli, U. (2019, Agustus 2). Anjuran Menyusui dalam 6 Agama. Dipetik Februari 20, 2020, dari Kumparan: https://kumparan.com/kumparan mom/anjuran-menyusui-dalam6-agama-1raSctVteqo

Sara, V. A., \& Elena, O. M. (2018). Aspek Psikososial Menyusui. Jurnal Ilmu Kedokteran Gigi.

Septiani, H., \& Heryani, S. (2019). Hubungan Tingkat Pendidikan Ibu Menyusui dengan Usia Penyapihan dalam Pemberian ASI pada Bayi Di Bawah Usia 1 tahun Wilayah Kerja Puskesmas Panumbangan.

Singgih, G. (2008). Dasar \& Teori Perkembangan Anak. Jakarta: PT BPK Gunung Mulia.

Sit, M. (2017). Psikologi Perkembangan Anak Usia Dini. Depok: Kencana.

Sunaryo. (2004). Psikologi untuk Keperawatan. Jakarta: Buku Kedokteran EGC.

Suryanto et al. (2012). Pengantar Psikologi Sosial. Surabaya: Airlangga University Press.
Susanti, I. Y. (2017). Penyapihan Dini dengan Status Gizi Anak Bawah Dua Tahun (BADUTA) di Posyandu Graha. Prosiding Seminar Nasional.

Sutanto, A. V. (2018). Asuhan Kebidanan Nifas dan Menyusui Teori dalam Paktik Kebidanan Profesional. Yogyakarta: Pustaka Baru Press.

Tine Donsu, J. D. (2019). Psikologi Keperawatan. Yogyakarta: Pustaka Baru.

Wasis. (2006). Pedoman Riset Praktis untuk Profesi Perawat. Jakarta: EGC.

Wenas, W., Malonda, N., Bolang, A., \& Kapantow, N. (2011). Hubungan antara Pengetahuan dan Sikap Ibu Menyusui dengan Pemberian ASI Eksklusif di wilayah kerja Puskesmas Tompaso Kecamatan Tompaso. Universitas Sam Ratulangi Manado.

Yuliarti, N. (2010). Keajaiban ASIMakanan Terbaik untuk Kesehatan,

Kecerdasan, dan Kelincahan $\mathrm{Si}$ Kecil. Yogyakarta: CV Andi Offset.

Yusuf, A., Nihayati, H. E., Iswari, M. F., \& Okviasanti, F. (2016).

Kebutuhan Spiritual Konsep dan Aplikasi dalam Asuhan Keperawatan. Jakarta: Mitra Wacana Medika. 